\title{
Calling all authors: Writing skills for family medicine residents in Kenya
}

\author{
S Onguka, ${ }^{1}$ MD; D M Basnight-Brown, ${ }^{2} \mathrm{PhD}$; V A Pallo, ${ }^{3} \mathrm{PhD}$; G M Wechuli, ${ }^{1}$ MMed-FM; M B Adam, ${ }^{4} \mathrm{MD}$ \\ ${ }^{1}$ Department of Family Medicine, School of Medicine and Health Sciences, Kabarak University, Kenya \\ ${ }^{2}$ Department of Psychology, School of Social Sciences, United States International University Africa, Nairobi, Kenya \\ ${ }^{3}$ Department of Focused Inquiry, University College, Virginia Commonwealth University, Richmond, VA, USA \\ ${ }^{4}$ Newborn Community Health Project, AIC Kijabe Hospital; and Institute of Healthcare Management, Strathmore Business School, Nairobi, Kenya
}

Corresponding author: S Onguka (educoord.fammed@kabarak.ac.ke)

\section{The problem}

Despite health research capacity growth in low- and middle-income countries (LMICs), the evidence for effective capacity-building strategies is lacking. ${ }^{[1]}$ Most studies describe efforts to strengthen research agendas and design, while authorship and writing competencies are overlooked. However, universities in Africa can play a powerful role in addressing these challenges. Master's theses of postgraduate medical residents in Kenya must be written in English; yet the students come from diverse language backgrounds without formal undergraduate writing instruction. Together with widely adopted courses in research methods, attention has to be given to postgraduate writing skill development to facilitate publication on a competitive global scale.

\section{The approach}

We are not aware of a curriculum where the unique writing skill needs of novice health researchers from LMICs are described. Our novel academic writing curriculum uses the six-step approach: ${ }^{[2]}$ (i) problem identification and general needs assessment; (ii) needs assessment of targeted learners; (iii) goals and objectives; (iv) educational strategies; ( $v$ ) implementation; and ( vi) evaluation and feedback. A general needs assessment was completed through an exhaustive literature search, while specific needs were informed by senior residents. Objectives of the curriculum were: (i) to strengthen knowledge and skills in academic writing; and (ii) to develop residents' confidence regarding writing and authorship. Educational strategies included collaborative learning, formative feedback, online programmed learning and reflection.

The 45-hour seminar was piloted, revised and then implemented among 5 first-year family medicine residents at Kabarak University, Kenya. For all 5 residents English was a second or third language. Live sessions focused on referencing skills and paragraph construction, introduction, methods, results, analysis and discussion (IMRAD) components, analysis and synthesis of articles, revising, editing and manuscript submission. Online activities targeted fundamental English writing skills and residents' reflections on writing. Formative written and oral feedback on writing assignments was integrated throughout the seminar. Curriculum evaluation explored knowledge, skills and attitudinal domains. On the first and last days, residents completed a 90-minute writing exercise to synthesise 2 articles on antibiotic stewardship. The scoring rubric was shaped and piloted by 3 expert reviewers to strengthen inter-rater reliability. Ten-point confidence scales were embedded in reflective writing assignments on: (i) ability to avoid plagiarism (before and after the seminar); and (ii) confidence in writing/being an author (before and after the seminar).

Ethical approval was obtained from Kabarak University.

\section{The outcome}

Residents demonstrated improved academic writing skills after the 45-hour seminar. Pre- and post-seminar group writing score means were $24 / 70$ (34\%)
Table 1. Residents' 10-point confidence scale responses

\begin{tabular}{llllll}
\hline & \multicolumn{2}{c}{ Avoiding plagiarism } & & \multicolumn{2}{c}{ Being an author } \\
\cline { 2 - 3 } \cline { 5 - 6 } Resident & Before & After & & Before & After \\
\hline A & 1 & 8 & & 3 & 8 \\
B & 1 & 8 & & 5 & 8 \\
C & 0 & 7 & & 2 & 6 \\
D & 1 & 7 & & 2 & 6 \\
E & 1 & 8 & & 3 & 7
\end{tabular}

and 40.3/70 (57\%), respectively. Despite meaningful gains, this revealed the need for longitudinal writing skill development across the entire programme. In the attitudinal domain, residents expressed greater confidence in avoiding plagiarism and being an author (Table 1). We suggest that the active learning methodologies and formative feedback were instrumental in the reported increase in self-efficacy. ${ }^{[3]}$ Our experience highlights the value of institutional collaboration in this effort, as most residency programmes have cohorts of $<10$ students. Both intra- and interinstitutional collaboration can allow broader curriculum implementation and evaluation among other postgraduate programmes, including the impact on African first-author publications.

\section{Declaration. None.}

Acknowledgements. Thanks to Dr Gundula Bosch, faculty, health professions programme at Johns Hopkins University, Baltimore, Md, USA, who assisted with the study design.

Author contributions. SO: literature search/review, study design, ethics review submission, data collection, first draft of manuscript; DMBB: data collection, statistical analysis, review of figures, revision of manuscript; VAP: data collection, review of figures, revision of manuscript; GMW: data collection, review of figures, revision of manuscript; MBA: study design, review of figures, revision of manuscript. Funding. None.

Conflicts of interest. None.

\footnotetext{
1. Franzen SR, Chandler C, Lang T. Health research capacity development in low and middle income countries: Reality or rhetoric? A systematic meta-narrative review of the qualitative literature. BMJ Open 2017;7(1):e012332. Reality or rhetoric? A systematic meta-narrative
https://doi.org/10.1136/bmjopen-2016-012332

2. Kern DE, Thomas PA, Hughes MT. Curriculum Development for Medical Education: A Six-Step Approach. 2nd ed. Baltimore, Md: JHU Press, 2009.

3. Kolb AY, Kolb DA. Learning styles and learning spaces: Enhancing experiential learning in higher
3. education. Acad Manage Learn Educ 2005;4(2):192-212. https://doi.org/10.5465/amle.2005.17268566
} 